\title{
Mobile Commerce (M-Commerce) Interface Design: A Review of Literature
}

\author{
Zaifulasraf Ahmad ${ }^{1}$, Roslina Ibrahim ${ }^{2}$ \\ ${ }^{1,2}$ (Advanced Informatics School/ UniversitiTeknologi Malaysia, Malaysia)
}

\begin{abstract}
Advances in wireless technology have led to rapid growth on various mobile services. This includes changes of shopping activities by the online shopper. Previously, shoppers use in-store shopping or through web shopping sites which is electronic commerce (e-commerce). Nowadays, with the increased use of smartphones and mobile application, the popularity of mobile commerce (m-commerce) is increased among consumer. Due to growth of m-commerce, it is crucial to ensure the m-commerce applications are highly usable and friendly. Therefore, it is important to properly design the interface of the apps. This paper discusses several interface design principles that m-commerce apps must follow in order to be a good apps. This paper provide the literature review for design guidelines based on several researches from databases such as IEEE. Science Direct, and Google Scholar. There are seven elements of m-commerce interface design such as context, content, community, customization, communication, connection and commerce elements has been found in this review.
\end{abstract}

Keywords: Interaction Design, Interface Guideline, Issues, Mobile Commerce, User Experience

\section{Introduction}

In developing markets across the world, the merging of rapidly growing economies and the advance in mobile services usage create new innovative services including $\mathrm{m}$-commerce. M-commerce is services or platform offers industry players to their consumer for various commerce activitiesby using mobile devices capacity. In other words, M-Commerce involved the transaction of information, services and goods through mobile devices between merchants and end-user or their customers in wireless communication technology.

Based on the statistics[1] for second quarter of 2015, there are 59\% among US adults spent their time on mobile but only $15 \%$ of their dollars spent on mobile which is $85 \%$ on desktop. However, they have problems in interface design which resulted on poor mobile shopping experience among the user, it's because of few factors[2]such as small screen size, speed, securityand the most importantly is many sites are not mobile optimized (customer experience) in term of interface design.

Previous researchers [3] also found that there are several issues in m-commerce that customers find it difficult to perform smooth activities or transaction using their mobile such as limited mobile memory, simplicity of user interface, screen size and small input method or keypad. In addition tothat, [3]suggested in order to plan or design a good mobile application interface, they must consider the few design factors such as the purpose of user's mobile device, characteristics of user, environment, satisfy the user's need from the system and system testing with the user. According to [4]there are few reasons why the adoption of m-commerce is slower than predicted such as the delay on technology standardization, limited internet coverage and poor service quality.

The good interface design require both elements from user perspective and also mobile devices constraint. It's not just, the developer can fit all the information in limited screen size of mobile[5]. The other researcher [6] believe that the m-commerce design have their own guidelines based on three categories of context such as m-commerce environment, participants (user) and activities that involved with m-commerce tasks and goals. The designer must understanding the interaction between those categories in order to achieve good m-commerce design.

Good interface design guideline can be used by company to increase usability and trust among user[7]. The important factor that bring the success of m-commerce is to ensure the user interface design can fulfill the customer's experience[8]. All the features of user interface design such as page (navigation menu, bars, button and icon) and content design including detail information, catalogue and shopping cart are the key factors of $\mathrm{m}$ commerce transaction and contribute for increase or decrease sales in online store[8]

\section{Research Methodology}

This study reviews the past researchesof m-commerce interface design.We have reviewed the papers searched from IEEE, Science Direct and Google Scholar database using related keywords. 
Fig. 1 describes the research path followed in this study.

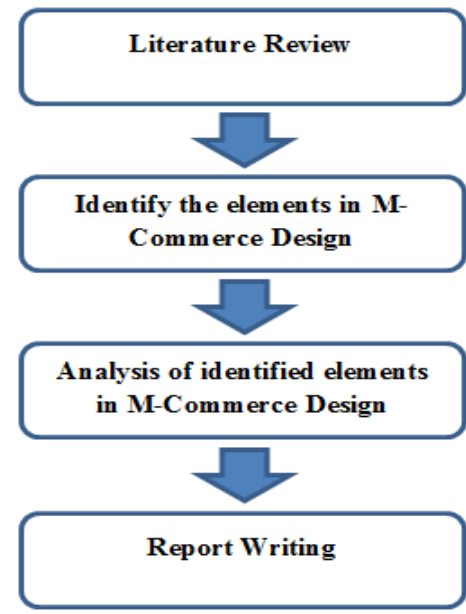

Fig. 1 : Research Methodology

\section{Review Of Literature}

Hadiana, 2016 adopts Kansei Engineering as a method in her research to translate the customer's feelings and impressions into m-commerce design[9]. As a result she found that there are six emotions of the customer that have higher value on this perspective which is glamour, dynamic, comfortable, passion, unique and cool whereby the dynamic and glamour on the top and second place that have highest value among them. All this emotions can be used as a reference in how to design the interface of m-commerce. At the final analysis, she identified the design concept of each significant element under the dynamic and glamour interface. The design concepts of dynamic interfaces are Background Color: Black, Header Color: Blue and Search Icon: Right. Meanwhile the design concepts of glamour are Background Color: Black, Header Color: Black and Search Icon: Right[9]. Tarasewich, 2003 categorize three elements in graphical representation of context model that can be used for m-commerce design[6]. The three elements are environment, participants and activities which linked to each other's by interaction that exist among them. The environment category is referring to availability and physical applications or devices and communications. The participant'scategory involves the user's physical characteristics and other elements inside the environment. Meanwhile activities category is mention about all activities or task that performs by participants in that environment. The designer must understand first this entire element on this model for example people and how they interact with each of others[6]. Gong \&Tarasewich, 2004 use Shneiderman's "Golden Rules of Interface Design" as a starting point for their reference in order to develop and propose their own guidelines for mobile interface design[10]. They proposed eight main guidelines for the mobile design whereby four of them from Shneiderman's including enable frequent users to use shortcuts, offer informative feedback, design dialogs to yield closure and support internal locus of control. The other four guidelines are consistency, reversal of actions, error prevention and simple error handling and reduce short-term memory load. All this guidelines are based on desktop interface design but it is accustomed to fulfill the unique features and limitation of mobile devices [10]. Chan, et al., 2002 recommend eight design guidelinesfor m-commerce application [11] as shown in Table 1.

Table 1 : The Recommended Design (Chan, et al., 2002)

\begin{tabular}{|c|c|}
\hline Design & Details \\
\hline Avoid scrolling, especially horizontal scrolling. & $\begin{array}{l}\text { It is better to limit the page length and format the page to fit the screen width in } \\
\text { order to avoid scrolling. }\end{array}$ \\
\hline Use a flat hierarchy & $\begin{array}{l}\text { Since every step takes longer on handheld devices, a flat hierarchical structure } \\
\text { with fewer steps is preferred. }\end{array}$ \\
\hline $\begin{array}{l}\text { Design a navigation system consistent with a regular } \\
\text { Web browser. }\end{array}$ & $\begin{array}{l}\text { The design of handheld devices and browsers running on them must adopt } \\
\text { similar metaphors and layout should resemble regular Web browsers. }\end{array}$ \\
\hline $\begin{array}{l}\text { Design a "Back" button with the same function as it } \\
\text { has in a regular browser. }\end{array}$ & $\begin{array}{l}\text { It is better to implement in wireless applications a "Back" function that is the } \\
\text { same as its counterpart on a regular browser. }\end{array}$ \\
\hline $\begin{array}{l}\text { Provide a history list that records the order in which } \\
\text { hyperlinks have been traversed. }\end{array}$ & The history list should present previously visited Web sites as a stack. \\
\hline $\begin{array}{l}\text { Provide indication of signal strength and downloading } \\
\text { progress on every screen. }\end{array}$ & Downloading progress help users determine the speed of data transmission. \\
\hline Do not require users to remember items. & $\begin{array}{l}\text { Provide appropriate navigation to bring users back to the data entry page after } \\
\text { reviewing the codes, or provide a help screen without leaving the data entry } \\
\text { screen. }\end{array}$ \\
\hline Limit the search scope to improve search efficiency. & $\begin{array}{l}\text { Improve the search precision by intelligent query support and predefined } \\
\text { search options. }\end{array}$ \\
\hline
\end{tabular}


Based on their research [11], they found that the main issue of wireless application (m-commerce) is because the applications need to be accessible using different platform that have different operating system and functionalities. In order to encounter the issue, the recommended design should consider few aspects for example the display of content in shorter length to avoid too much scrolling and create the navigation system similar with web browser[11].

Cyra, Headb, \&Ivanovc, 2006confirmed that the design aesthetics in m-commerce positively influence to perceived usefulness, perceived of use and perceived enjoyment[12]. All these factorsare significantly impact to m-loyalty which is how user willingness to re-visit the m-commerce application. Aesthetics is referring to how our brain interprets with something good or bad in their first appearance. In context of m-commerce, the interface design can be expressed via colors, shape, font type, music or animation. All this elements will influence the sensory experience of m-commerce and will attract more customers[12].

Tarasewich, 2002 believe that the well-designed of user interface and perceived usability are important aspect for user to perform smooth activities in m-commerce[13]. Those factors will influence user to stay longer and invite them to return back. He categorized the interaction between user and wireless devices (mobile) by two types, input interaction (the capabilities of users using mobile application to enter any data or commands) and output interaction (how users receive the outcome from application). All this capabilities and limitations should been analyzed first and then the usability of those interface can be identified and tested. He found that, there are several methods to evaluate the usability including empirical testing, heuristic evaluations, cognitive walkthroughs and analytics method[13].

Tobing, et al., 2016 suggested there are three main features of m-commerce such as products catalog, shopping cart function and payment function[14]. The design of product catalog must have pictures of product, name of product, description of product, price and discount of product, category of product and also product search function. Meanwhile the shopping cart will come after the selection of product or between the process whereby customer can add, edit, delete and check their total price of the ordered item. The last process which is payment function must have capability to collect customer information, keep track the order and provide the option of payment method[14].

Feng, Jia, \& Wang, 2010 classified the mobile e-commerce (m-commerce) design by three main categories which are business system description, system architecture design and application design and analysis[15]. In business system description, the important elements are system sign-on (customer registration and login), updated product information and inquiries, order process transaction and submission to commerce platform (database) in e-Commerce business system. Meanwhile system architecture design involves the server-side, client and communication network. The third category is application design and analysis. There are five modules in this category which are data modeling design (customer table, product table, price table etc.), login module (login interface), product query module (product information), orders (purchasing transaction) and data update (data synchronization for customer and product on m-commerce system database[15].

In focusing on the m-commerce issue, Lee \&Benbasat, 2003 proposed seven design elements of customer interface as per Table 2 to be considered in $\mathrm{m}$-commerce design in order to improve the quality of the application and attract more customers[4].

\begin{tabular}{|c|c|c|}
\hline \multirow[b]{2}{*}{$\begin{array}{l}\text { 7Cs of Interface } \\
\text { Implementation } \\
\end{array}$} & \multicolumn{2}{|r|}{ M-Commerce } \\
\hline & $\begin{array}{c}\text { Mobile Setting } \\
\text { To support consumers; limited attention }\end{array}$ & $\begin{array}{c}\text { Mobile Device Constraints } \\
\text { To complement the insufficient display of mobile devices }\end{array}$ \\
\hline Context & $\begin{array}{l}\text { Menu structured in a shallow rather than a } \\
\text { deep hierarchy Layered sequential process } \\
\text { rather than field selection process }\end{array}$ & $\begin{array}{l}\text { Summary and keywords that give a whole picture of } \\
\text { information separated over pages. }\end{array}$ \\
\hline Content & $\begin{array}{l}\text { Proximate selection method that makes nearby } \\
\text { located-objects easier to choose (gas stations, } \\
\text { bank accounts) }\end{array}$ & $\begin{array}{l}\text { Conversion of visual information to audio format Use of } \\
\text { non-speech sound }\end{array}$ \\
\hline Community & $\begin{array}{l}\text { Connection to shopping companions who } \\
\text { share interests in common }\end{array}$ & $\begin{array}{l}\text { SMS, and graphics describing products, transferred through a } \\
\text { user's phone book }\end{array}$ \\
\hline Customization & $\begin{array}{l}\text { Proximate selection method that emphasizes } \\
\text { the object of interests, by combining a user's } \\
\text { mobile setting (location, time, and resource) } \\
\text { with his or her personal interests }\end{array}$ & $\begin{array}{l}\text { Personalized service based on known user profile (content } \\
\text { and layout configuration without a need of log-in } \\
\text { registration) }\end{array}$ \\
\hline Communication & $\begin{array}{l}\text { Targeted advertising suitable at the point-of- } \\
\text { purchase }\end{array}$ & $\begin{array}{l}\text { Customer feedback in multiple-answer or multimedia } \\
\text { formats }\end{array}$ \\
\hline Connection & $\begin{array}{l}\text { Adaptive map that shows the information } \\
\text { about nearby stores }\end{array}$ & $\begin{array}{l}\text { The icon that gives a link to the starting page with one-click } \\
\text { of 'cancel' button }\end{array}$ \\
\hline Commerce & Insertion of authentication into mobile phones & $\begin{array}{l}\text { One-click checkout process made available by storing a } \\
\text { consumer's address, payment method, preferred delivery } \\
\text { options }\end{array}$ \\
\hline
\end{tabular}

Table 2 : The Seven Design Elements of the M-Commerce Customer Interface (Lee \&Benbasat, 2003) 
Based on that table, they proposed seven elements for m-commerce design including context, content, community, customization, communication, connection and commerce. Each of those elements has been analyzed by two viewpoints which are mobile setting (to support customer's need) and mobile device setting (to match with limitation of mobile device). All the result from this table can be used as mobile design reference because it's already catered to fit with two characteristics of m-commerce[4].

\section{IV. discussion}

From the review of those studies, each of researcher use different approach in how to propose the user interface guideline; for exampleHadiana, 2016 come out with two design concept which is dynamic and design concept that has similarity with background color and search icon[9]. Meanwhile Chan, et al., 2002 propose eight design guidelines that involve the page format design, flat structure, navigation, button, history list signal, remembering item and search query[11]. Tobing, et al., 2016 concentrate on commerce activities in mobile platform such as catalogue and payment site[14]. From this example of research paper, we can see that each of them have their own view in order to propose the good m-commerce interface design. However, Lee \& Benbasat, 2003 in their research combined the entire factor that related with m-commerce application into 7Cs which is context, content, community, customization communication connection and commerce[4]. They make sure all these elements are uniquely to m-commerce concept that has their own limitation compare with ecommerce (website design). Fig. 2 describes the seven design elements of m-commerce interface implementation.

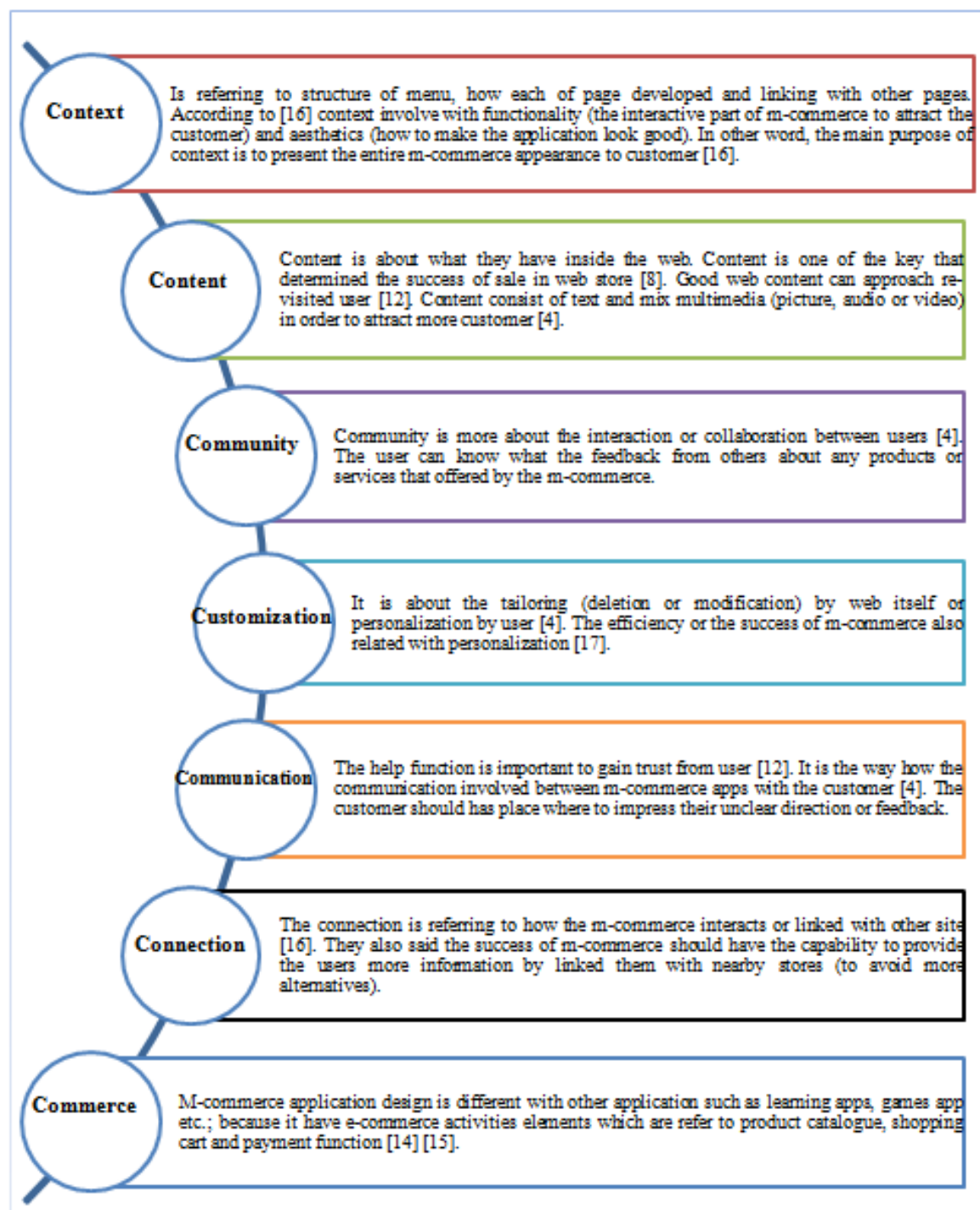

Fig. 2: Seven Design Elements of M-Commerce Interface Implementation 


\section{Conclusion}

The aim of this paper is to review the elements of m-commerce design that proposed by different research paper. All the elements were identified and analyzed based on the criteria and limitation of physical mobile devices such as mobile phone, palm and tablet. Not only focus on the devices itself, but user experience also the important aspect in m-commerce design to gain and increase the usability and trust among them. The study found that all this elements can be categorized by $7^{\prime} \mathrm{Cs}$ of $\mathrm{m}$-commerce element. The limitation of this study is we cannot find the differentiate between mobile operating system such as Apple iOS, Google Android, BlackBerry OS, Nokia's Symbian or Microsoft's Windows Phone OS. We believe that different mobile OS has the own concept and restriction that can influence on m-commerce design. Meanwhile, the result of the study may help the industry players toadopt and maximize the m-commerce design in effective way in order to maintain their existing customer and to increase more customers to gain more profit in online store. The mobile application including $\mathrm{m}$-commerce application is growing rapidly and the rapid competition in industry is a sign to them to improve the proficiency of their m-commerce design.

\section{References}

[1] A. Meola, "http://www.businessinsider.com/," 21 December 2016. [Online]. Available: http://www.businessinsider.com/mobilecommerce-shopping-trends-stats-2016-10?IR=T\&r=US\&IR=T.

[2] P. Tarasewich, R. C.Nikerson and M. Warkentin, "Issues in Mobile E-Commerce," Communications of the Association for Information Systems, vol. 8, pp. 41-64, 2002.

[3] N. Z. b. Ayob, A. R. C. Hussin and H. M. Dahlan, "Three Layers Design Guideline for Mobile Application," 2009 International Conference on Information Management and Engineering, pp. 427-431, 2009.

[4] Y. E. Lee and I. Benbasat, "Interface Design for Mobile Commerce," Communications of the ACM - Mobile computing opportunities and challenges, vol. 46, pp. 48-52, 01 December 2003.

[5] J. Buranatrived and P. Vickers, "An investigation of the impact of mobile phone and PDA interfaces on the usability of mobilecommerce applications," Proceedings 3rd IEEE International Workshop on System-on-Chip for Real-Time Applications, pp. 90-95, 30 October 2002.

[6] P. Tarasewich, "Designing Mobile Commerce Applications," Communications of the ACM - Mobile computing opportunities and challenges, vol. 46, pp. 57-60, 01 December 2003.

[7] Y.-S. Y. Yung-Ming Li, "Increasing trust in mobile commerce through design aesthetics," Computers in Human Behavior, vol. 26, no. 4, pp. 673-684, July 2010.

[8] V. Venkatesh, V. Ramesh and A. P. Massey, "Understanding usability in mobile commerce," Communications of the ACM, vol. 46, no. 12, pp. 53-56, December 2003.

[9] A. Hadiana, "Kansei analysis of interface's elements for mobile commerce application," 2016 4th International Conference on Information and Communication Technology (ICoICT), pp. 1-4, 2016.

[10] J. Gong and P. Tarasewich, "Guidelines for handheld mobile device interface design," pp. 3751-3756, 2004.

[11] S. S. Chan, X. Fang, J. Brzezinski, Y. Zhou, S. Xu and J. Lam, "Usability for Mobile Commerce Across Multiple Form Factors," Journal of Electronic Commerce Research,, vol. 3, pp. 187-199, 2002.

[12] D. Cyra, M. Headb and A. Ivanovc, "Design aesthetics leading to m-loyalty in mobile commerce," Information \& Management, vol. 43, pp. 950-963, 2006

[13] P. Tarasewich, "Wireless Devices for Mobile Commerce: User Interface Design and Usability," in Mobile Commerce: Technology, Theory, and Applications, Idea Group Inc (IGI), 2002, pp. 26-50.

[14] R. D. H. Tobing, L. V. D. Pardede, I. S. Panjaitan and E. Y. Sianturi, "Customizable commerce mobile application," Computer and Information Sciences (ICCOINS), 2016 3rd International Conference, pp. 174-178, 2016.

[15] X.-j. Feng, J. Jia and H.-d. Wang, "Client Designing for Mobile E-commerce System Based on .NET," 2010 Second International Conference on Computer Modeling and Simulation, vol. 2, pp. 407 - 410, 2010.

[16] Y. E. Lee and I. Benbasat, "A Framework for the Study of Customer Interface Design fo Mobile Commerce," International Journal of Electronic Commerce, vol. 8, pp. 79-101, 2004.

[17] U. Varshney, "Business Models for Mobile Commerce Services: Requirements, Design, and the Future," IT Professional, vol. 10, no. 6, pp. 48-55, 09 January 2008. 